\title{
Bone Biopsy for Histomorphometry in Chronic Kidney Disease (CKD): State-of-the-Art and New Perspectives
}

\author{
Luca Dalle Carbonare ${ }^{1, *(\mathbb{D}}$, Maria Teresa Valenti ${ }^{1}\left(\mathbb{D}\right.$, Sandro Giannini ${ }^{2}\left(\mathbb{D}\right.$, Maurizio Gallieni ${ }^{3,4} \mathbb{D}^{\mathbb{D}}$, \\ Francesca Stefani ${ }^{1}$, Roberto Ciresa ${ }^{1}$, Cristina Politi ${ }^{5}$ and Maria Fusaro ${ }^{6,7}$ (D) \\ 1 Section of Internal Medicine, Department of Medicine, University of Verona, 37134 Verona, Italy; \\ mariateresa.valenti@univr.it (M.T.V.); stefani.francesca.a@gmail.com (F.S.); roberto.ciresa.rc@gmail.com (R.C.) \\ 2 Clinica Medica 1, Department of Medicine, University of Padova, 35128 Padova, Italy; \\ sandro.giannini@unipd.it \\ 3 L. Sacco' Department of Biomedical and Clinical Sciences, Università degli Studi di Milano "La Statale", \\ 20157 Milano, Italy; maurizio.gallieni@unimi.it \\ 4 Nephrology and Dialysis Unit, “L. Sacco" Hospital, ASST Fatebenefratelli-Sacco, 20157 Milano, Italy \\ 5 CNR-IFC of Reggio Calabria, Section of Clinical Epidemiology and Biostatistics, 89124 Reggio Calabria, Italy; \\ politicristina89@gmail.com \\ 6 National Research Council (CNR), Institute of Clinical Physiology (IFC), 56124 Pisa, Italy; \\ dante.lucia11@gmail.com \\ 7 Department of Medicine, University of Padova, 35128 Padova, Italy \\ * Correspondence: luca.dallecarbonare@univr.it; Tel.: +39-045-8126062; Fax: +39-045-8027496
}

Citation: Dalle Carbonare, L.; Valenti, M.T.; Giannini, S.; Gallieni, M.; Stefani, F.; Ciresa, R.; Politi, C.; Fusaro, M. Bone Biopsy for Histomorphometry in Chronic

Kidney Disease (CKD):

State-of-the-Art and New Perspectives. J. Clin. Med. 2021, 10, 4617. https://doi.org/10.3390/ jcm10194617

Academic Editor: Juan

F. Navarro-González

Received: 7 September 2021

Accepted: 4 October 2021

Published: 8 October 2021

Publisher's Note: MDPI stays neutral with regard to jurisdictional claims in published maps and institutional affiliations.

Copyright: (c) 2021 by the authors. Licensee MDPI, Basel, Switzerland. This article is an open access article distributed under the terms and conditions of the Creative Commons Attribution (CC BY) license (https:/ / creativecommons.org/licenses/by/ $4.0 /)$.

\begin{abstract}
The use of bone biopsy for histomorphometric analysis is a quantitative histological examination aimed at obtaining quantitative information on bone remodeling, structure and microarchitecture. The labeling with tetracycline before the procedure also allows for a dynamic analysis of the osteoblastic activity and mineralization process. In the nephrological setting, bone biopsy is indicated to confirm the diagnosis of subclinical or focal osteomalacia and to characterize the different forms of renal osteodystrophy (ROD). Even if bone biopsy is the gold standard for the diagnosis and specific classification of ROD, the use of this approach is very limited. The main reasons for this are the lack of widespread expertise in performing or interpreting bone biopsy results and the cost, invasiveness and potential pain associated with the procedure. In this regard, the sedation, in addition to local anesthesia routinely applied in Italian protocol, significantly reduces pain and ameliorates the pain perception of patients. Concerning the lack of widespread expertise, in Italy a $\mathrm{Hub} /$ Spokes model is proposed to standardize the analyses, optimizing the approach to CKD patients and reducing the costs of the procedure. In addition, new tools offer the possibility to evaluate the osteogenic potential or the ability to form bone under normal and pathological conditions, analyzing mesenchymal stem cells and their ability to differentiate in the osteogenic lineage. In the same way, circulating microRNAs are suggested as a tool for exploring osteogenic potential. The combination of different diagnostic approaches and the optimization of the bioptic procedure represent a concrete solution to spread the use of bone biopsy and optimize CKD patient management.
\end{abstract}

Keywords: bone biopsy; histomorphometry; kidney; osteodystrophy; ROD

\section{Introduction}

The use of bone biopsy for histomorphometric analysis is a quantitative histological examination aimed at obtaining information on bone remodeling, structure and microarchitecture [1] (Figure 1).

Histomorphometric analyses are classified into structural, microarchitectural and remodeling parameters, with the latter subdivided into static and dynamic categories. The labeling with tetracycline before the procedure also allows a dynamic analysis of osteoblastic activity and mineralization processes [2] (Figure 2). Metabolic bone disorders show different histomorphometric patterns and this approach characterizes and confirms 
the diagnosis of different metabolic diseases such as sub-clinical or focal osteomalacia, hyperparathyroidism [3], or other endocrine diseases [4], osteoporosis and different forms of renal osteodystrophy (ROD) [5,6]. From another point of view, bone histomorphometry analyses are indicated to clarify cases of unexplained fragility fractures or to evaluate the effects of different treatments on bone, such as antiresorptive or anabolic drugs and their potential side effects [7], as well as the activity of new drugs used for the treatment of metabolic bone diseases [8].

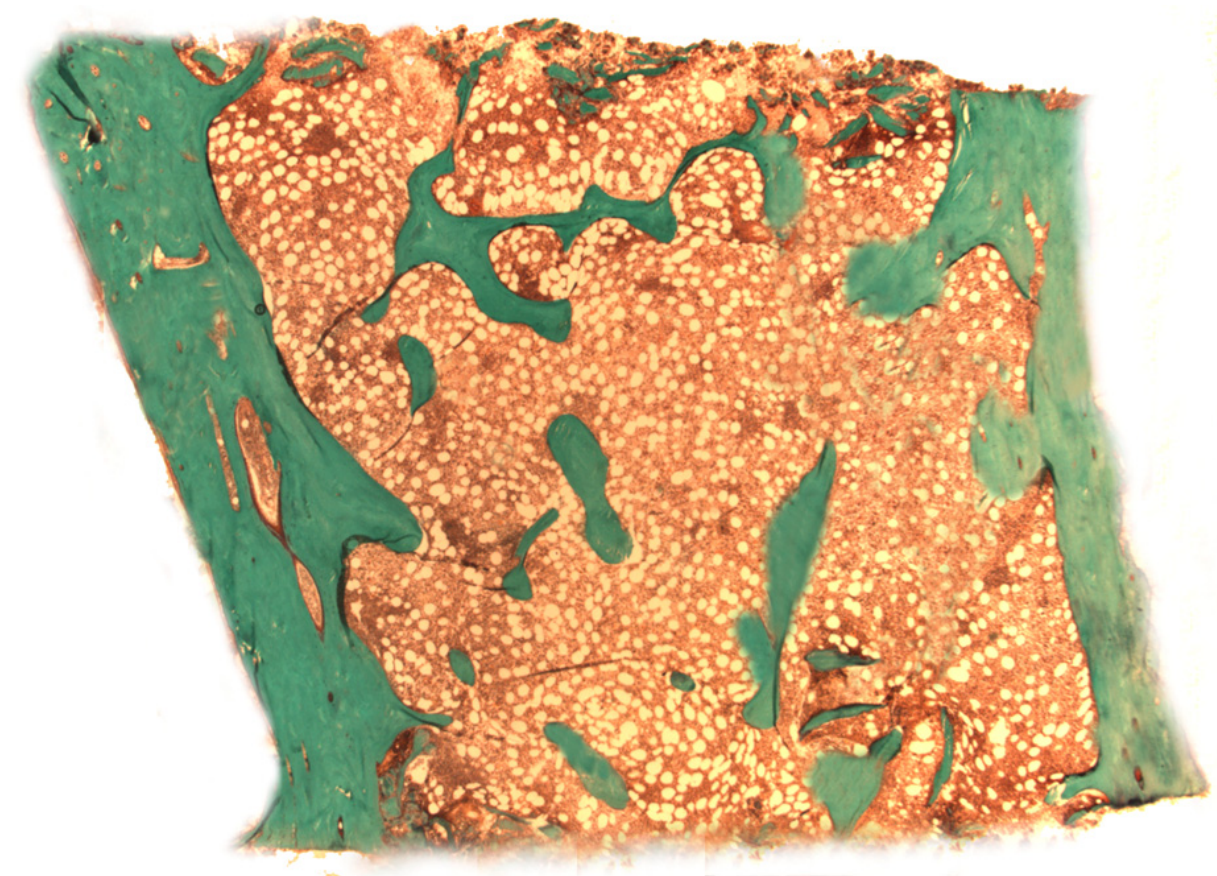

Figure 1. Representation of a Goldner trichrome-stained bone section. In green: the mineralized matrix, in red: the osteoid.

Bone and mineral metabolism alterations are common in chronic kidney disease (CKD) and they are part of a complex systemic osteoporotic condition affecting bone and vascular health, defined by Kidney Disease Improving Global Outcomes (KDIGO) guidelines as Chronic Kidney Disease Mineral and Bone Disorder (CKD-MBD). Until today, bone histomorphometry is the gold standard for the diagnosis of ROD during CKD, providing information that is not available by any other diagnostic approach [9].

In recent decades the definition, classification and treatment of ROD were changed as a consequence of the introduction of new drugs and the prolonged survival of patients (Table 1 [4,10-23]). Indeed, Malluche et al. highlighted [18], in 630 bone biopsies carried out in CKD patients, both in Europe and the USA, from 2003 to 2008, a switch from a high bone turnover, as revealed in the past studies, to $58 \%$ of patients with a low bone turnover. These findings could be correlated with the introduction, in 2004, of drugs such as calcimimetics, resulting in excessive bone suppression. In fact, contrasting data were recently published by the Brazilian electronic database (REBRABO) [12] collected from 2015 to 2018, in which the authors found that $50 \%$ of the 260 patients with CKD 3-5D had Osteitis Fibrosa. Most likely, among the causes of these results, as specified by the authors, it is necessary to keep in mind the availability of drugs used for the treatment of CKD-MBD [12]. 


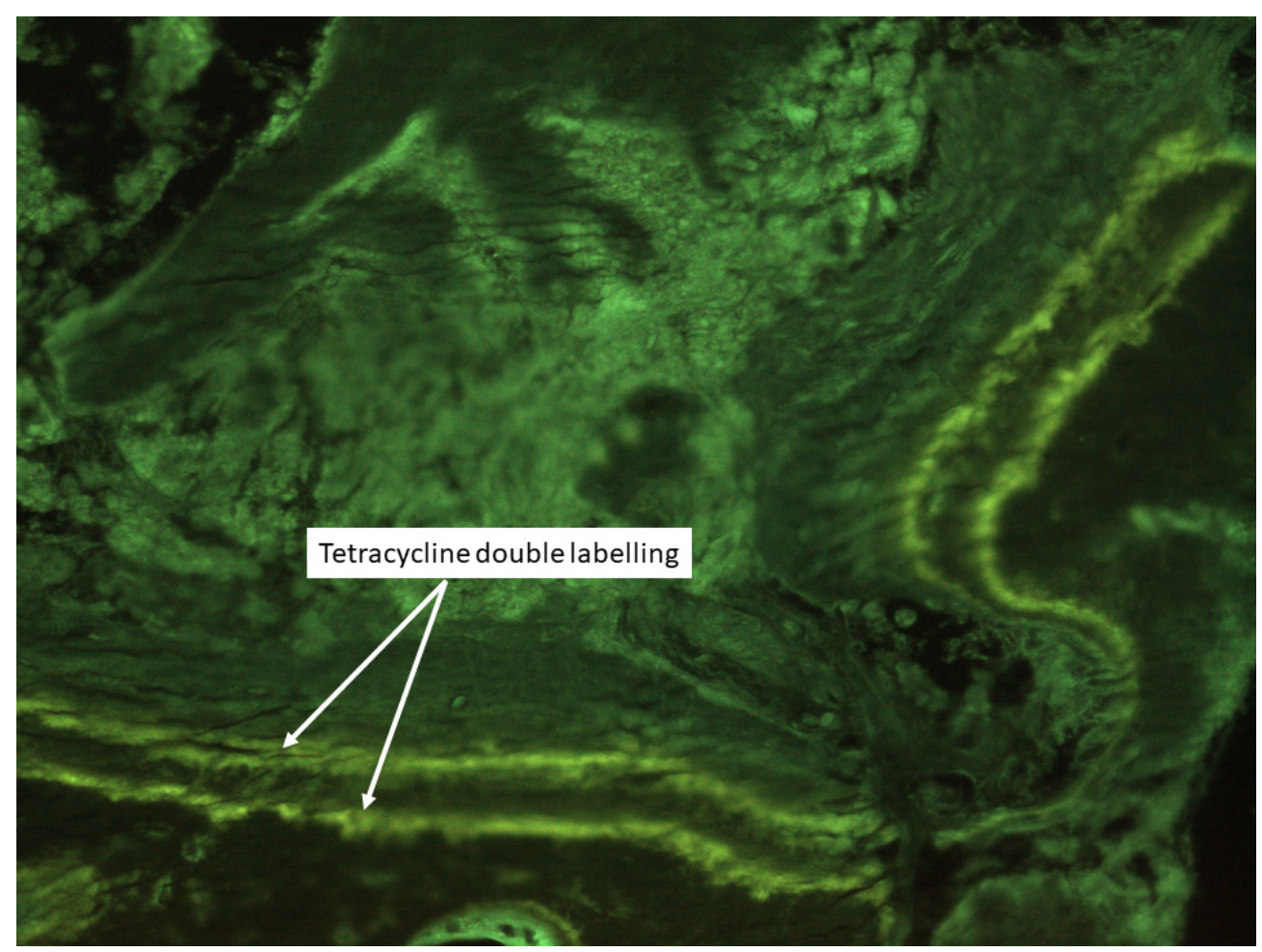

Figure 2. Example of double tetracycline labelling. The two green lines represent the mineralization surfaces while the Mineral Apposition Rate is the distance between the two lines expressed in microns.

Table 1. The main literature on bone biopsy in recent decades.

\begin{tabular}{|c|c|c|c|c|}
\hline Authors & Design of the Study & Number of Patients & Type of Bone Disease & Journal, Year \\
\hline Aaltonen et al. & Observational & $\begin{array}{l}n=26 \\
\text { ESRD }\end{array}$ & $\begin{array}{c}61 \% \text { low, } 27 \% \text { normal, } \\
12 \% \text { high } \\
\text { bone turnover }\end{array}$ & Calcif Tissue Int. 2021 \\
\hline Lavigne et al. & Observational & $\begin{array}{l}n=11 \\
\text { CKD }\end{array}$ & $\begin{array}{c}45.4 \% \text { adynamic } \\
\text { bone disease } \\
18.1 \% \text { high } \\
18.1 \% \text { mixed renal } \\
\text { osteodystrophy } \\
9.1 \% \text { osteomalacia } \\
9.1 \% \text { not defined }\end{array}$ & $\begin{array}{l}\text { J Nephrol. } \\
2021\end{array}$ \\
\hline Salam et al. & Cross-sectional & $\begin{array}{c}n=43 \\
\text { CKD stages IV-V }\end{array}$ & $\begin{array}{c}40 \% \text { high, } 34 \% \text { normal, } \\
26 \% \text { low } \\
\text { bone turnover }\end{array}$ & $\begin{array}{l}\text { Bone, } \\
2021\end{array}$ \\
\hline Carbonara et al. & Observational & $\begin{array}{c}n=260 \\
\text { CKD stages III-V }\end{array}$ & High bone turnover & $\begin{array}{l}\text { J. Bras. Nefrol. } \\
2020\end{array}$ \\
\hline Novel-Catin et al. & Observational & $n=68$, ESRD & $\begin{array}{c}45 \% \text { Osteitis fibrosa } \\
21 \% \text { Mixed uremic } \\
\text { osteodystrophy } \\
12 \% \text { Adynamic bone disease } \\
10 \% \text { Osteomalacia }\end{array}$ & $\begin{array}{l}\text { Bone, } \\
2020\end{array}$ \\
\hline Liangos et al. & Observational & $\begin{array}{l}\text { 33, CKD stage III-V } \\
53 \text {, on hemodialysis }\end{array}$ & $\begin{array}{l}\text { High-turnover mixed uremic } \\
\text { osteodystrophy }\end{array}$ & $\begin{array}{l}\text { Kidney Blood Press Res. } \\
2018\end{array}$ \\
\hline Sharma et al. & Observational & $14, \mathrm{CKD}$ stage V & $\begin{array}{l}50 \% \text { high, } 29 \% \text { normal, } \\
21 \% \text { low bone turnover }\end{array}$ & $\begin{array}{l}\text { Am J Nephrol, } \\
2018\end{array}$ \\
\hline
\end{tabular}


Table 1. Cont.

\begin{tabular}{|c|c|c|c|c|}
\hline Authors & Design of the Study & Number of Patients & Type of Bone Disease & Journal, Year \\
\hline Evenepoel et al. & Observational & 36, kidney transplant & $\begin{array}{l}44.4 \% \text { low, } 52.8 \% \text { normal, } \\
2.8 \% \text { high bone turnover }\end{array}$ & $\begin{array}{l}\text { Kidney Int., } \\
2017\end{array}$ \\
\hline Sprague et al. & Cross-sectional & 492 , on hemodialysis & $\begin{array}{l}59 \% \text { low, } 24 \% \text { normal, } \\
17 \% \text { high bone turnover }\end{array}$ & Am J Kidney Dis., 2016 \\
\hline Malluche et al. & Observational & $630, \mathrm{CKD}$ stage $\mathrm{V}$ & $\begin{array}{c}58 \% \text { low, } 24 \% \text { high, } 18 \% \\
\text { normal bone turnover }\end{array}$ & $\begin{array}{l}\text { JBMR } \\
2011\end{array}$ \\
\hline Lehmann et al. & Observational & $\begin{array}{l}\text { 36, CKD stages III-IV } \\
\text { 92, CKD stage V }\end{array}$ & $\begin{array}{l}47.2 \% \text { Osteitis fibrosa } \\
61.4 \% \text { Osteitis fibrosa }\end{array}$ & $\begin{array}{l}\text { Clin Nephrol, } \\
2008\end{array}$ \\
\hline Miller et al. & Observational & 6, CKD stages IV-V & $\begin{array}{c}33 \% \text { low, } 33 \% \text { high } \\
\text { bone turnover, } \\
33 \% \text { osteomalacia }\end{array}$ & $\begin{array}{l}\text { CJASN } \\
2008\end{array}$ \\
\hline Coen et al. & Observational & 107, on hemodialysis & $\begin{array}{c}69 \% \text { mixed osteodystrophy } \\
11 \% \text { adynamic bone disease } \\
2.5 \% \text { hyperparathyroidism } \\
1 \% \text { osteomalacia } \\
57 \% \text { hyperparathyroidism } \\
28 \% \text { mixed osteodystrophy } \\
11 \% \text { adynamic bone disease } \\
2.8 \% \text { osteomalacia }\end{array}$ & $\begin{array}{l}\text { Nephron, } \\
2002\end{array}$ \\
\hline Gerakis et al. & Observational & 62, on hemodialysis & $\begin{array}{c}\text { 64.5\% hyperparathyroidism } \\
22.6 \% \text { adynamic bone } \\
\text { disease } \\
9.7 \% \text { mixed bone disease } \\
3.2 \% \text { osteomalacia }\end{array}$ & $\begin{array}{l}\text { J Nephrol., } \\
2000\end{array}$ \\
\hline Jørgensen et al. & Observational & 205, kidney transplan & $\begin{array}{c}24 \% \text { low, } 60 \% \text { normal, } \\
16 \% \text { high turnover }\end{array}$ & $\begin{array}{l}\text { Bone, } \\
2021\end{array}$ \\
\hline
\end{tabular}

ESRD: End Stage Renal Disease; CKD: Chronic Kidney Disease.

In addition, CKD patients with one or more fragility fractures are challenging to treat, firstly, due to the need to determine whether a patient is affected by osteoporosis and/or the various forms of metabolic bone diseases and, secondly, to choose the best therapeutic approach. The information regarding the actual prevalence of different types of ROD is conflicting. These discrepancies can be attributed to many factors, such as differences in the epidemiological and clinical characteristics of the CKD patients (such as age or ethnicity), the availability of drugs used for the treatment of CKD-MBD and different therapeutic strategies.

For this reason, it is of great importance to have reliable and reproducible diagnostic tools aimed at adequately addressing these complications.

\section{ROD and Bone Markers}

ROD is characterized by abnormalities of calcium, phosphate, parathyroid hormone (PTH), vitamin D metabolism, bone turnover, mineralization, volume or strength, as well as by the presence of vascular or soft tissue calcifications.

The evaluation of bone metabolism, and in particular bone turnover markers, is a useful tool in the management of metabolic bone diseases, but in ROD is not always sufficiently accurate, particularly in presence of low turnover bone diseases for which formation markers, such as bona alkaline phosphatase, are not predictive [24].

Recently, the European Society for Pediatric Nephrology, CKD-MBD and Dialysis and CKD-MBD working groups of the ERA-EDTA stated that, in the pediatric population, the currently available non-invasive measures, including biomarkers of bone, were affected by growth and pubertal status and had a limited sensitivity and specificity in predicting 
changes in bone turnover and mineralization [25]. This was an important limitation in the management of pediatric patients with CKD.

In summary, we conclude that the evaluation of bone turnover markers, particularly bone alkaline phosphatase can be useful when marked alterations are observed [26].

Key message: In borderline cases, the accuracy of markers is low and inadequate for the management of CKD patients.

\section{ROD and PTH}

The parathyroid hormone (PTH) was considered a pivotal marker in the diagnosis and management of ROD. As for turnover markers, the role of this parameter in CKD was recently reconsidered, taking into account its low accuracy in low-turnover renal bone disease $[27,28]$.

In the past, a desired PTH level between 150 and $300 \mathrm{pg} / \mathrm{mL}$ was suggested for dialysis patients. However, bone biopsy studies showed that a low bone turnover can be seen within this range and sometimes even with higher PTH levels. In a recent study, according to the K/DOQI PTH ranges, 15 patients out of $40(40 \%)$ with iPTH $>300 \mathrm{pg} / \mathrm{mL}$ showed an histomorphometric pattern of low turnover $[13,14]$. Accordingly, the 2017 KDIGO guidelines suggested that the measurements of serum PTH should be coupled to bone-specific alkaline phosphatase. Together they could be used to evaluate bone disease, but only markedly high or low values predicted the underlying bone turnover [29]. In addition, the same guidelines indicated that, in patients with CKD stages $3 a, 3 b, 4$, and 5 not on dialysis, the optimal PTH level was not known.

Key message: PTH had a poor predictive power in the low-turnover disease in CKD.

\section{ROD and Osteoporosis}

Dual X-rays absorptiometry (DXA) is considered the gold standard for the diagnosis of osteoporosis and it is one of the main predictors of fragility fractures [28]. The impossibility of measuring trabecular and cortical BMD separately and the interference of aortic calcifications in the measurement of vertebral BMD limit the possibility to adequately classify bone disease in CKD in adults and in adolescents [30], as well as to predict fractures, even using ultrasound techniques [31,32].

The Word Health Organization Osteoporosis defines osteoporosis as a reduction in bone density expressed as a T-score lower than -2.5 Standard Deviation (SD) compared to normal population (at the peak of bone mass). This diagnosis can be made independently of bone mass in the presence of fragility fractures. Indeed, bone strength is the result of a combination of bone density and bone quality, consisting of bone microarchitecture, turnover and mineralization. The disorders in bone quality can explain the finding that about half of all osteoporotic fractures occur in patients with T scores $>-2.5 \mathrm{SD}$. However, ROD is characterized by an alteration of bone quality regardless of bone loss [33].

Key message: The evaluation of bone density in CKD patients is not always predictive of bone fragility [26]. In fact, DXA provides a two-dimensional evaluation of a threedimensional structure and offers a very poor spatial resolution [34].

\section{ROD and Non-Invasive Diagnostic Approach}

Different non-invasive approaches were proposed to optimize the management of patients with ROD and different grades of bone fragility [35]. Indeed, the unclear efficacy in predicting fractures of DXA and its inability to specify types of renal osteodystrophy encourages scientific research to identify other non-invasive diagnostic strategies to manage CKD patients. The additional, novel applications for DXA analysis such as Trabecular Bone Score (TBS,) or other approaches such as high-resolution imaging tools, for example peripheral quantitative computed tomography (HR-pQCT), are used to evaluate the effects of kidney disease on cortical, trabecular microarchitecture and bone strength and to adequately predict the risk of fracture [36]. The data are encouraging but it is still debated whether the addition of $\mathrm{pQCT}$ or high-resolution pQCT parameters to DXA effectively 
improves fracture discrimination [37]. However, pQCT has a nominal spatial resolution of about $100 \mathrm{mc}$ [38] and a good signal-to-noise ratio, while bone histomorphometry offers a spatial resolution around the micron and represents, from this perspective, a much more accurate method for evaluating microarchitecture [1].

A combination of different approaches were also proposed to ameliorate the prognostic ability [39]. In this study the authors found that the combination of QCT, DXA and serum biochemical parameters such as PTH, sclerostin, and TRAP-5b (even if not still routine evaluations), were independent predictors of bone loss in patients with CKD-5D and ameliorated the prognostic power of clinical evaluations in these patients.

Key message: In general, none of non-invasive approaches demonstrated an adequate diagnostic accuracy for CKD [40].

\section{ROD and Bone Biopsy}

The use of bone biopsy for histomorphometric analysis is the only technique providing the following specific information: (1) the study of bone at the three levels: cells, tissue and Basic Multicellular Units (BMU, Figure 3); (2) the direct evaluation of the turnover at the trabecular level; (3) the static and dynamic evaluation of bone turnover using double tetracycline labelling (Figure 2); and (4) the evaluation of microarchitecture through direct and indirect parameters (Figure 4).

The diagnosis and management of ROD is an important clinical challenge. For this reason, the tetracycline, double-labelled, transiliac bone biopsy for histology and a histomorphometric analysis remains the best clinical approach to describe the static and dynamic parameters of bone turnover and to also evaluate the other qualitative aspects of renal osteodystrophy [41].

Even though this approach was the gold standard for the diagnosis of ROD, a recent European survey showed that bone biopsies were performed rather exceptionally, both for clinical and research purposes. In particular, the clinical research concerning ROD was threatened by the limited availability of technical, clinical and pathological expertise, small patient cohorts, and scientific isolation [42].

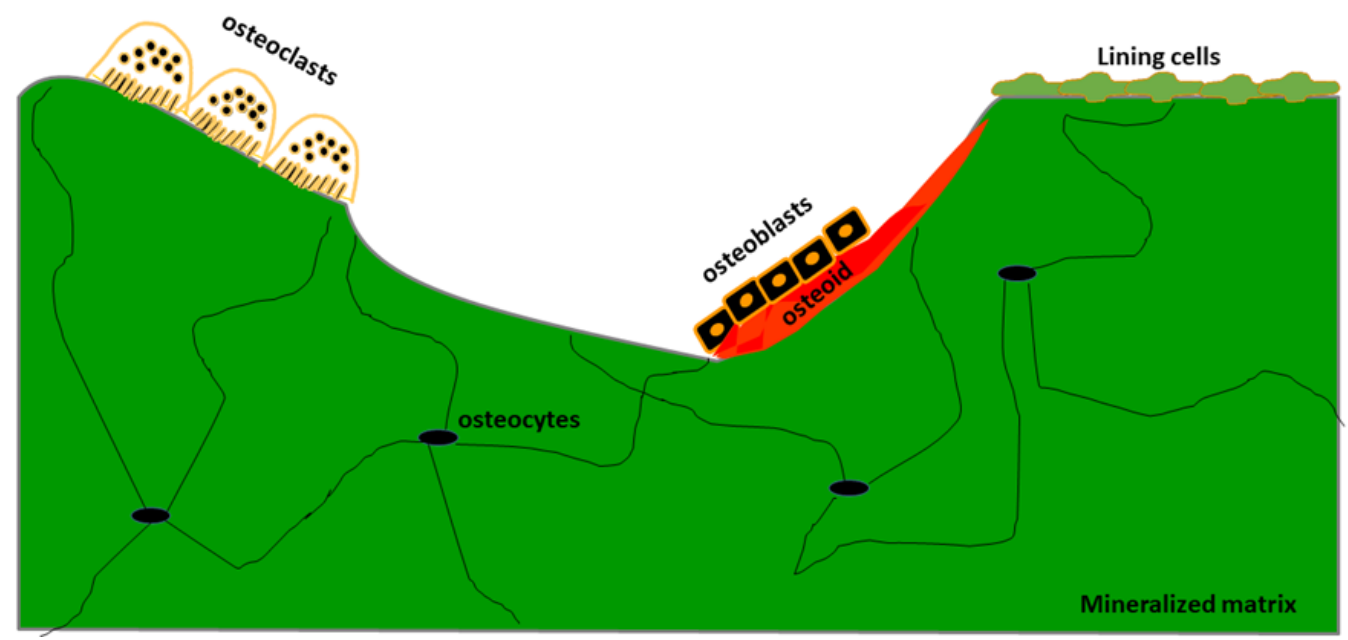

Figure 3. Schematic representation of Bone Multicellular Unit (BMU). 


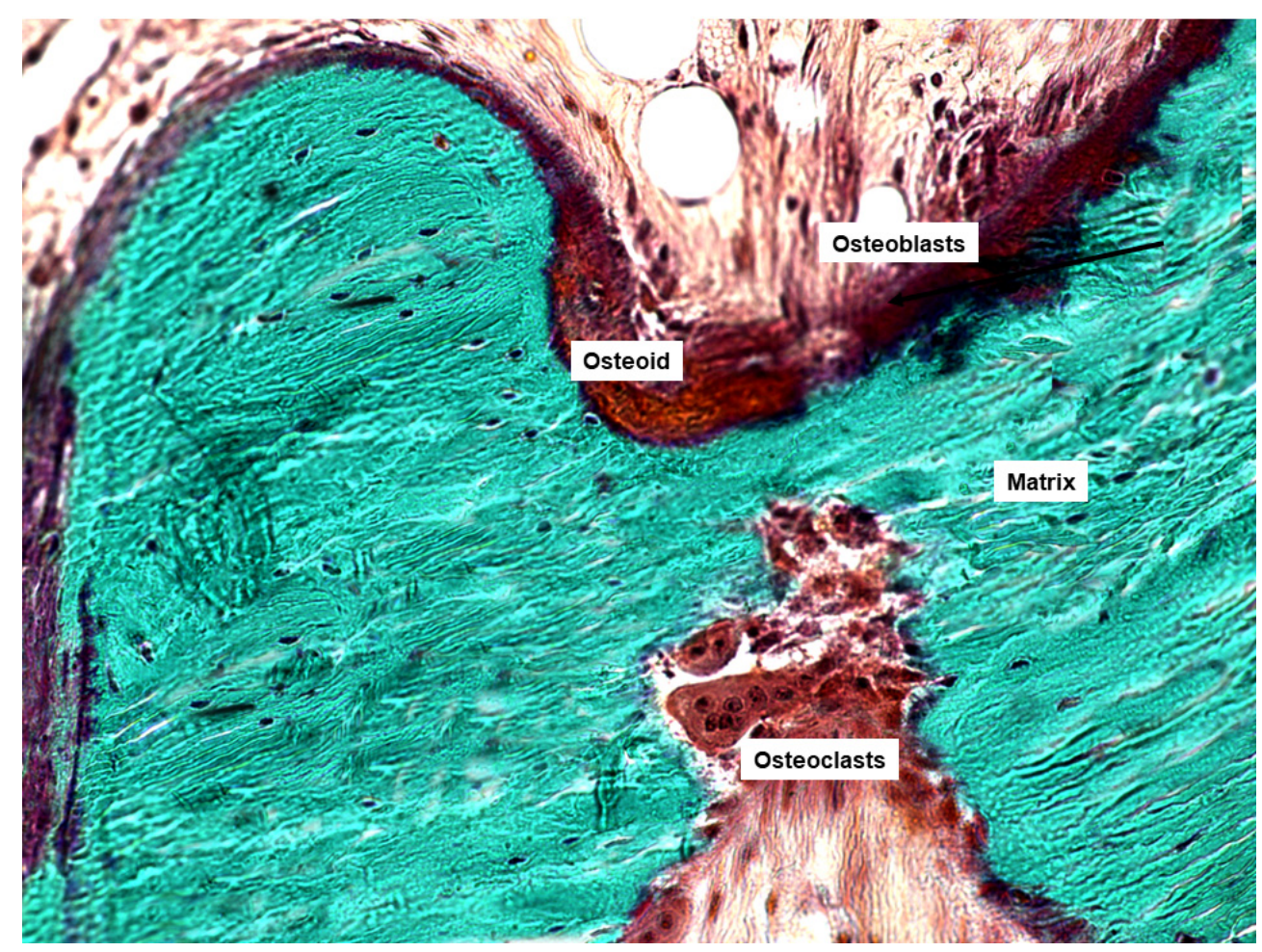

Figure 4. Goldner trichrome-stained bone section in which we can see osteoblasts, osteoclasts and osteoid, the main product of osteoblasts.

\section{Indications of Bone Biopsy in CKD}

Several years ago, the Kidney Disease Improving Global Outcomes (KDIGO) revised the indications of bone biopsy underlying the importance of this approach for the correct classification and the adequate treatment [43].

Recently, the same group revised the guidelines of CKD compared to those of 2009, specifying that, in patients with CKD G3a-G5D, it was reasonable to perform a bone biopsy if knowledge of the type of renal osteodystrophy would impact treatment decisions [42].

On the basis of these most recent findings and consensus statements, we summarized the main indications for bone biopsy in Table 2 [42].

Table 2. Synthetic updated indications for bone biopsy in CKD.

(1) In patients with CKD G3a-G5D, it is reasonable to perform a bone biopsy if knowledge of the type of renal osteodystrophy will impact treatment decisions (evidence not graded)

(2) In patients with CKD G3a-G5D with biochemical abnormalities of CKD-MBD and low BMD and/or fragility fractures, we suggest that treatment choices take into account the magnitude and reversibility of the biochemical abnormalities and the progression of CKD, with consideration of a bone biopsy (evidence 2D).

(3) During the first 12 months after kidney transplant, in patients in with an estimated glomerular filtration rate greater than approximately $30 \mathrm{~mL} / \mathrm{min} / 1.73 \mathrm{~m}^{2}$ and a low $\mathrm{BMD}$, it is reasonable to consider a bone biopsy to guide treatment (evidence not graded).

\section{Classification of ROD by Histomorphometry}

Based on the different histomorphometric parameters, the bone disease during CKD was classified taking into account three compartments: turnover, mineralization and volume [41]. The turnover reflected the rate of skeletal remodelling, mineralization described the effectiveness of bone collagen becoming calcified during the formation phase of skeletal remodelling and volume indicated the amount of bone per unit volume of tissue. By using this approach, we could characterize different types of ROD as follows: adynamic bone disease and osteomalacia (low turnover diseases) and osteitis fibrosa and mixed uremic 
osteodystrophy (high turnover diseases), independently from bone turnover markers or PTH (Figure 5).
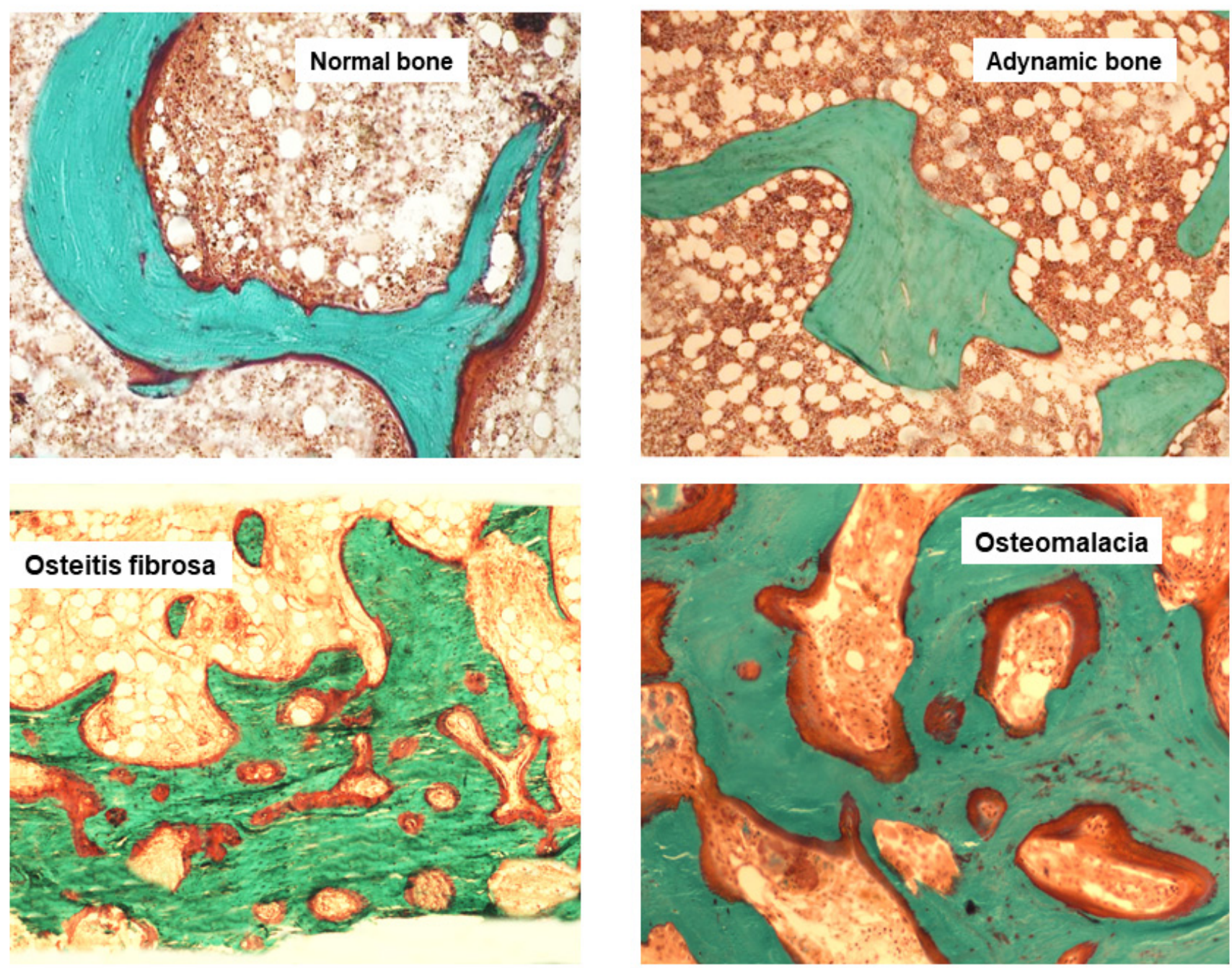

Figure 5. Goldner trichrome-stained bone section representing the main histomorphometric patterns of Renal Osteodystrophy ROD.

\section{Limitations of Bone Biopsy}

Even if, at present, bone biopsy remains the gold standard for the diagnosis and specific classification of renal osteodystrophy (ROD), the use of this approach is very limited. The main reasons for the infrequent use of bone biopsy, other than the lack of widespread expertise in performing or interpreting bone biopsy results and the high costs, are the invasiveness and potential pain associated with the procedure. In this regard, various solutions are proposed, e.g., the use of fluoroscopy for a more precise localization of the biopsy site and the standardization of the intervention [10] or the use of a smaller trephine providing a halved biopsy [12].

In our opinion, the first approach can ameliorate the issues with bone biopsy, but the availability of interventional radiologists is limited and this would hamper the wider application of the method. For the second proposal, according to the previous authors, we believe that smaller samples may result in the loss of information, particularly in terms of turnover, but can be useful for monitoring the treatment or in the follow-up of patients already diagnosed and characterized through a standard biopsy [43]. 
From another point of view, the use of sedation, in addition to local anesthesia, routinely applied in Italian protocol, significantly reduces pain and ameliorates the negative perceptions of patients.

Concerning the lack of widespread expertise in performing and interpreting bone biopsy, with the support of the Italian Scientific Society of Osteoporosis and Mineral Metabolism Diseases of the Skeleton and of the Italian Nephrology Society, a Hub/Spokes model is proposed to centralize and standardize the analyses, as well as to facilitate the shipment of the bioptic samples to the two hubs, Rome and Verona, creating a national network and optimizing the approach to CKD patients and reducing the costs of the analyses.

\section{New Perspectives}

In addition to the histomorphometric evaluation of bone samples, it is important to know the osteogenic potential of a specific subject or the ability of bone to renew itself under normal and pathological conditions, particularly in CKD.

In recent years, the studies aimed at evaluating mesenchymal stem cells, as well as studies conducted to evaluate molecular markers involved in osteogenic differentiation, ensured the understanding of osteogenic potential in a given physiological or pathological context.

Mesenchymal stem cells (MSCs) are undifferentiated cells able to differentiate to different cellular lineages such as osteoblastic, chondrocyte or adipocyte cells. In particular, specific cellular signals can induce the gene expression of the osteoblastic master gene, RUNX2, which, by activating specific downstream genes, such as the transcription factor SP7, directs MSCs in an osteogenic sense [44]. In osteoporotic patients, an increased number of circulating MSCs associated with a reduced expression of RUNX2, SP7 and osteoblastic maturation-associated genes suggests an impaired osteogenic potential of these patients [45]. Therefore, the molecular profile associated with mesenchymal cells reflects the osteogenic potential in an individual. Importantly, circulating MSCs are non-invasive biomarkers as they can be obtained from a peripheral blood sample [46,47].

Epigenetic alteration, such as the methylation and acetylation of DNA and histones is involved in the aging process. It was demonstrated that KAT6A, an enzyme responsible for histone acetylation, acted as a transcriptional coactivator of RUNX2 and that the alterations of KAT6 impaired skeleton genesis [48]. Recently, it was demonstrated that KAT6A regulated the aging of MSCs and counteracted ROS accumulation through the Nrf2/ ARE signaling pathway [48]. Thus, a lower KAT6 expression reduced the osteogenic potential of the MSCs and the investigations of this marker in circulating MSCs allowed knowledge of the osteogenic potential. In addition, circulating microRNAs (miR), which were small, non-coding molecules, were suggested as a tool for exploring osteogenic potential. miR223, miR148a, miR31, miR21-5p and miR503 were just some of the markers associated with osteoclastic activity while miR322, miR181, miR143, miR 182 and miR155 were involved in osteoblastic activity [49]. Thus, an individual, circulating microRNA profile could reflect the osteogenic potential. In addition, the long and non-coding RNAs (lncRNAs), i.e., RNA molecules with a length of $>200$ nucleotides, regulated gene expression in different cellular processes and it was observed that lncRNAs were associated with osteogenesis and bone diseases [50-52]. The lncRNA targeting DANCR was observed in human circulating monocytes [53]. As DANCR correlated to IL6 and TNF $\alpha$ in patients affected by osteoporosis it was suggested that the long and non-coding RNA-DANCR could be used as a biomarker in osteoporosis [53]. The implementation of bone biopsy with such non-invasive approaches for the study of bone osteogenic precursors could further improve the diagnostic accuracy in this specific setting.

\section{Conclusions}

The use of bone biopsy remains the gold standard in the diagnosis of metabolic bone diseases, particularly in CKD patients. 
The Italian bone biopsy protocol, as well as the built network based on the hub/spoke model, can ameliorate the appeal of this procedure, standardize the results, and create a national database optimizing the management of patients with metabolic bone diseases.

\section{Highlights}

- $\quad$ Bone and mineral metabolism alterations are common in chronic kidney disease (CKD);

- In borderline cases, the accuracy of markers are low and inadequate for the management of CKD patients;

- $\quad$ PTH has a poor predictive power in low turnover disease in CKD;

- In CKD patients, the predictive powers of Bone Densitometryand non-invasive approaches are low because they provide a two-dimensional evaluation of a threedimensional structure, and thus offer a very poor spatial resolution;

- The use of bone biopsy is the gold standard for the diagnosis and specific classification of Renal Osteodystrophy (ROD);

- The Italian biopsy protocol, as well as the built network based on the hub/spoke model, can ameliorate the appeal of this procedure.

Author Contributions: L.D.C., M.T.V., S.G., M.G. and M.F., conception and design of the work; F.S., R.C. and C.P., acquisition and analysis of data; L.D.C., M.T.V., F.S. and R.C. draft of the work; L.D.C. and M.F., revision of the work. All authors have read and agreed to the published version of the manuscript.

Funding: This research received no external funding.

Institutional Review Board Statement: Not applicable.

Informed Consent Statement: Not applicable.

Conflicts of Interest: The authors declare no conflict of interest. All authors declare that there are no financial and non-financial competing interests.

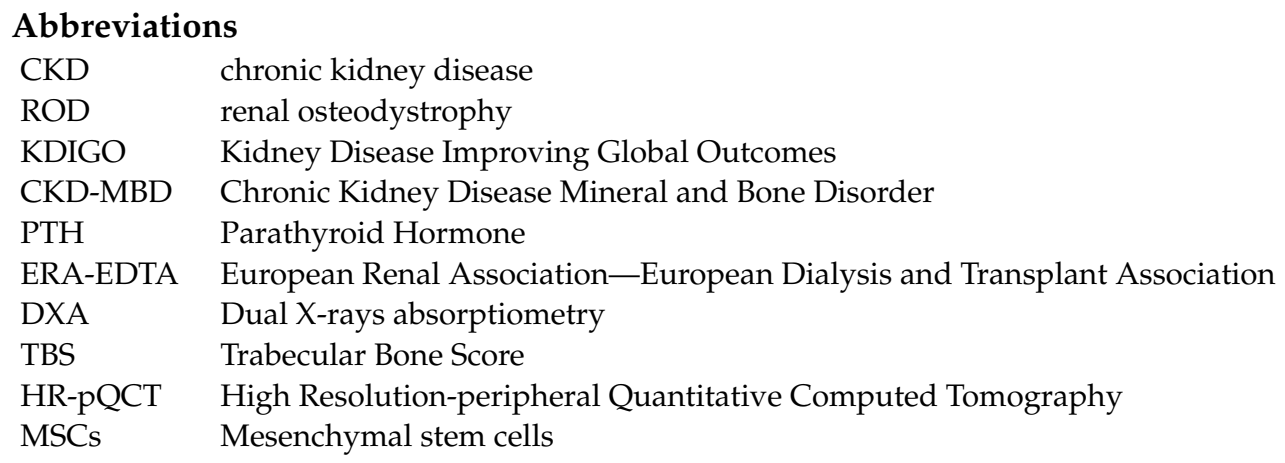

\section{References}

1. Carbonare, L.D.; Valenti, M.; Bertoldo, F.; Zanatta, M.; Zenari, S.; Realdi, G.; Cascio, V.L.; Giannini, S. Bone microarchitecture evaluated by histomorphometry. Micron 2005, 36, 609-616. [CrossRef]

2. Carbonare, L.D.; Giannini, S. Histologic diagnosis of metabolic bone diseases: Bone histomorphometry. Reumatismo 2004, 56, 15-23. [CrossRef]

3. Carbonare, L.D.; Ballanti, P.; Bertoldo, F.; Valenti, M.T.; Giovanazzi, B.; Giannini, S.; Realdi, G.; Cascio, V.L. Trabecular bone microarchitecture in mild primary hyperparathyroidism. J. Endocrinol. Investig. 2008, 31, 525-530. [CrossRef]

4. Salam, S.; Gallagher, O.; Hughes, D.; Khwaja, A.; Eastell, R. The role of static bone histomorphometry in diagnosing renal osteodystrophy. Bone 2021, 142, 115689. [CrossRef]

5. Ramalho, J.; Marques, I.; Hans, D.; Dempster, D.; Zhou, H.; Patel, P.; Pereira, R.; Jorgetti, V.; Moyses, R.; Nickolas, T.L. The trabecular bone score: Relationships with trabecular and cortical microarchitecture measured by HR-pQCT and histomorphometry in patients with chronic kidney disease. Bone 2018, 116, 215-220. [CrossRef] [PubMed]

6. Bedogni, A.; Saia, G.; Bettini, G.; Tronchet, A.; Totola, A.; Bedogni, G.; Tregnago, P.; Valenti, M.T.; Bertoldo, F.; Ferronato, G.; et al. Osteomalacia: The Missing Link in the Pathogenesis of Bisphosphonate-Related Osteonecrosis of the Jaws? Oncologist 2012, 17, 1114-1119. [CrossRef] 
7. Recker, R.; Dempster, D.; Langdahl, B.; Giezek, H.; Clark, S.; Ellis, G.; De Villiers, T.; Valter, I.; Zerbini, C.A.; Cohn, D.; et al. Effects of Odanacatib on Bone Structure and Quality in Postmenopausal Women with Osteoporosis: 5-Year Data from the Phase 3 Long-Term Odanacatib Fracture Trial (LOFT) and its Extension. J. Bone Miner. Res. 2020, 35, 1289-1299. [CrossRef]

8. Evenepoel, P.; Behets, G.; Laurent, M.; D'Haese, P. Update on the role of bone biopsy in the management of patients with CKD-MBD. J. Nephrol. 2017, 30, 645-652. [CrossRef] [PubMed]

9. Aaltonen, L.; Koivuviita, N.; Seppänen, M.; Burton, I.S.; Kröger, H.; Löyttyniemi, E.; Metsärinne, K. Bone Histomorphometry and 18F-Sodium Fluoride Positron Emission Tomography Imaging: Comparison Between only Bone Turnover-based and Unified TMV-based Classification of Renal Osteodystrophy. Calcif. Tissue Int. 2021, 1-10. [CrossRef]

10. Lavigne, F.; Desbiens, L.-C.; Garneau, G.; Côté, F.; Mac-Way, F. Iliac crest bone biopsy by interventional radiologists to improve access to bone biopsy in chronic kidney disease populations: Technical note and a case series. J. Nephrol. 2021, 34, 901-906. [CrossRef] [PubMed]

11. Carbonara, C.E.M.; Dos Reis, L.M.; Quadros, K.R.D.S.; Roza, N.A.V.; Sano, R.; Carvalho, A.B.; Jorgetti, V.; De Oliveira, R.B. Renal osteodystrophy and clinical outcomes: Data from the Brazilian Registry of Bone Biopsies-REBRABO. Braz. J. Nephrol. 2020, 42, 138-146. [CrossRef]

12. Novel-Catin, E.; Pelletier, S.; Fouque, D.; Roux, J.-P.; Chapurlat, R.; D’Haese, P.; Behets, G.; Evenepoel, P.; Nickolas, T.L.; Lafage-Proust, M.-H. Quantitative histomorphometric analysis of halved iliac crest bone biopsies yield comparable ROD diagnosis as full 7.5mm wide samples. Bone 2020, 138, 115460. [CrossRef]

13. Liangos, O.; Kirchhoff, S.; Buchholz, J.; Ketteler, M. Bone Biopsy Results in Chronic Kidney Disease: A Single-Center Experience. Kidney Blood Press. Res. 2018, 43, 1222-1230. [CrossRef] [PubMed]

14. Sharma, A.; Toussaint, N.D.; Masterson, R.; Holt, S.G.; Rajapakse, C.S.; Ebeling, P.R.; Mohanty, S.T.; Baldock, P.; Elder, G.J. Deterioration of Cortical Bone Microarchitecture: Critical Component of Renal Osteodystrophy Evaluation. Am. J. Nephrol. 2018, 47, 376-384. [CrossRef] [PubMed]

15. Evenepoel, P.; Behets, G.J.; Viaene, L.; D'Haese, P.C. Bone histomorphometry in de novo renal transplant recipients indicates a further decline in bone resorption 1 year posttransplantation. Kidney Int. 2017, 91, 469-476. [CrossRef] [PubMed]

16. Sprague, S.M.; Bellorin-Font, E.; Jorgetti, V.; Carvalho, A.B.; Malluche, H.H.; Ferreira, A.; D’Haese, P.C.; Drueke, T.B.; Du, H.; Manley, T.; et al. Diagnostic Accuracy of Bone Turnover Markers and Bone Histology in Patients With CKD Treated by Dialysis. Am. J. Kidney Dis. 2016, 67, 559-566. [CrossRef]

17. Malluche, H.H.; Mawad, H.W.; Monier-Faugere, M.-C. Renal osteodystrophy in the first decade of the new millennium: Analysis of 630 bone biopsies in black and white patients. J. Bone Miner. Res. 2011, 26, 1368-1376. [CrossRef]

18. Lehmann, G.; Ott, U.; Kämmerer, D.; Schütze, J.; Wolf, G. Bone histomorphometry and biochemical markers of bone turnover in patients with chronic kidney disease Stages 3-5. Clin. Nephrol. 2008, 70, 296-305. [CrossRef]

19. Miller, P.D. The Role of Bone Biopsy in Patients with Chronic Renal Failure. Clin. J. Am. Soc. Nephrol. 2008, 3, S140-S150. [CrossRef]

20. Coen, G.; Ballanti, P.; Bonucci, E.; Calabria, S.; Costantini, S.; Ferrannini, M.; Giustini, M.; Giordano, R.; Nicolai, G.; Manni, M.; et al. Renal Osteodystrophy in Predialysis and Hemodialysis Patients: Comparison of Histologic Patterns and Diagnostic Predictivity of Intact PTH. Nephron 2002, 91, 103-111. [CrossRef]

21. Gerakis, A.; Hadjidakis, D.; Kokkinakis, E.; Apostolou, T.; Raptis, S.; Billis, A. Correlation of bone mineral density with the histological findings of renal osteodystrophy in patients on hemodialysis. J. Nephrol. 2000, 13, 437-443.

22. Jørgensen, H.S.; Behets, G.; Viaene, L.; Bammens, B.; Claes, K.; Meijers, B.; Naesens, M.; Sprangers, B.; Kuypers, D.; D’Haese, P.C.; et al. Static HISTOMORPHOMETRY allows for a diagnosis of bone turnover in renal OSTEODYSTROPHY in the absence of tetracycline labels. Bone 2021, 152, 116066. [CrossRef]

23. Gerakis, A.; Hutchison, A.; Apostolou, T.; Freemont, A.; Billis, A. Biochemical markers for non-invasive diagnosis of hyperparathyroid bone disease and adynamic bone in patients on haemodialysis. Nephrol. Dial. Transplant. 1996, 11, $2430-2438$. [CrossRef]

24. Bakkaloglu, S.A.; Bacchetta, J.; Lalayiannis, A.D.; Leifheit-Nestler, M.; Stabouli, S.; Haarhaus, M.; Reusz, G.; Groothoff, J.; Schmitt, C.P.; Evenepoel, P.; et al. Bone evaluation in paediatric chronic kidney disease: Clinical practice points from the European Society for Paediatric Nephrology CKD-MBD and Dialysis working groups and CKD-MBD working group of the ERA-EDTA. Nephrol. Dial. Transplant. 2021, 36, 413-425. [CrossRef]

25. Khairallah, P.; Nickolas, T.L. Management of Osteoporosis in CKD. Clin. J. Am. Soc. Nephrol. 2018, 13, 962-969. [CrossRef] [PubMed]

26. Barreto, F.; Barreto, D.; Moysés, R.; Neves, K.; Canziani, M.; Draibe, S.; Jorgetti, V.; Carvalho, A. K/DOQI-recommended intact PTH levels do not prevent low-turnover bone disease in hemodialysis patients. Kidney Int. 2008, 73, 771-777. [CrossRef]

27. Moore, C.; Yee, J.; Malluche, H.; Rao, D.S.; Monier-Faugere, M.-C.; Adams, E.; Daramola-Ogunwuyi, O.; Fehmi, H.; Bhat, S.; Osman-Malik, Y. Relationship between Bone Histology and Markers of Bone and Mineral Metabolism in African-American Hemodialysis Patients. Clin. J. Am. Soc. Nephrol. 2009, 4, 1484-1493. [CrossRef] [PubMed]

28. Jannot, M.; Mac-Way, F.; Lapierre, V.; Lafage-Proust, M.-H. The use of bone mineral density measured by dual energy X-ray absorptiometry (DXA) and peripheral quantitative computed microtomography in chronic kidney disease. J. Nephrol. 2017, 30, 635-643. [CrossRef] [PubMed] 
29. Wang, A.Y.-M.; Akizawa, T.; Bavanandan, S.; Hamano, T.; Liew, A.; Lu, K.-C.; Lumlertgul, D.; Oh, K.-H.; Zhao, M.-H.; Fung, S.; et al. 2017 Kidney Disease: Improving Global Outcomes (KDIGO) Chronic Kidney Disease-Mineral and Bone Disorder (CKD-MBD) Guideline Update Implementation: Asia Summit Conference Report. Kidney Int. Rep. 2019, 4, 1523-1537. [CrossRef] [PubMed]

30. Bianchi, M.L.; Baim, S.; Bishop, N.J.; Gordon, C.M.; Hans, D.B.; Langman, C.B.; Leonard, M.B.; Kalkwarf, H.J. Official positions of the International Society for Clinical Densitometry (ISCD) on DXA evaluation in children and adolescents. Pediatr. Nephrol. 2010, 25, 37-47. [CrossRef]

31. Jamal, S.A.; Chase, C.; Goh, Y.; Richardson, R.; Hawker, G.A. Bone density and heel ultrasound testing do not identify patients with dialysis-dependent renal failure who have had fractures. Am. J. Kidney Dis. 2002, 39, 843-849. [CrossRef]

32. Christoforidis, A.; Printza, N.; Gkogka, C.; Siomou, E.; Challa, A.; Kazantzidou, E.; Kollios, K.; Papachristou, F. Comparative study of quantitative ultrasonography and dual-energy X-ray absorptiometry for evaluating renal osteodystrophy in children with chronic kidney disease. J. Bone Miner. Metab. 2011, 29, 321-327. [CrossRef]

33. Moe, S.M. Renal Osteodystrophy or Kidney-Induced Osteoporosis? Curr. Osteoporos. Rep. 2017, 15, 194-197. [CrossRef] [PubMed]

34. Bover, J.; Ureña-Torres, P.; Cozzolino, M.; Rodríguez-García, M.; Gómez-Alonso, C. The Non-invasive Diagnosis of Bone Disorders in CKD. Calcif. Tissue Int. 2021, 108, 512-527. [CrossRef] [PubMed]

35. Shevroja, E.; Lamy, O.; Hans, D. Review on the Utility of Trabecular Bone Score, a Surrogate of Bone Micro-architecture, in the Chronic Kidney Disease Spectrum and in Kidney Transplant Recipients. Front. Endocrinol. 2018, 9, 561. [CrossRef] [PubMed]

36. Pocock, N. Use of dual energy X-ray absorptiometry, the trabecular bone score and quantitative computed tomography in the evaluation of chronic kidney disease-mineral and bone disorders. Nephrology 2017, 22, 19-21. [CrossRef] [PubMed]

37. Geusens, P.; Chapurlat, R.; Schett, G.; Ghasem-Zadeh, A.; Seeman, E.; De Jong, J.; Bergh, J.V.D. High-resolution in vivo imaging of bone and joints: A window to microarchitecture. Nat. Rev. Rheumatol. 2014, 10, 304-313. [CrossRef]

38. Carvalho, C.; Alves, C.M.; Frazão, J.M. The role of bone biopsy for the diagnosis of renal osteodystrophy: A short overview and future perspectives. J. Nephrol. 2016, 29, 617-626. [CrossRef]

39. Evenepoel, P.; D’Haese, P.; Bacchetta, J.; Cannata-Andia, J.; Ferreira, A.; Haarhaus, M.; Mazzaferro, S.; Lafage-Proust, M.-H.; Salam, S.; Spasovski, G.; et al. Bone biopsy practice patterns across Europe: The European renal osteodystrophy initiative-A position paper. Nephrol. Dial. Transplant. 2017, 32, 1608-1613. [CrossRef]

40. Malluche, H.H.; Davenport, D.L.; Cantor, T.; Monier-Faugere, M.-C. Bone Mineral Density and Serum Biochemical Predictors of Bone Loss in Patients with CKD on Dialysis. Clin. J. Am. Soc. Nephrol. 2014, 9, 1254-1262. [CrossRef]

41. Moe, S.; Drüeke, T.; Cunningham, J.; Goodman, W.; Martin, K.; Olgaard, K.; Ott, S.; Sprague, S.; Lameire, N.; Eknoyan, G. Definition, evaluation, and classification of renal osteodystrophy: A position statement from Kidney Disease: Improving Global Outcomes (KDIGO). Kidney Int. 2006, 69, 1945-1953. [CrossRef]

42. Ketteler, M.; Block, G.A.; Evenepoel, P.; Fukagawa, M.; Herzog, C.A.; McCann, L.; Moe, S.M.; Shroff, R.; Tonelli, M.; Toussaint, N.D.; et al. Executive summary of the 2017 KDIGO Chronic Kidney Disease-Mineral and Bone Disorder (CKD-MBD) Guideline Update: What's changed and why it matters. Kidney Int. 2017, 92, 26-36. [CrossRef] [PubMed]

43. Moore, R.J.; Durbridge, T.C.; Woods, A.E.; Vernon-Roberts, B. Comparison of two bone trephine instruments used for quantitative histomorphometry. J. Clin. Pathol. 1989, 42, 213-215. [CrossRef] [PubMed]

44. Carbonare, L.D.; Innamorati, G.; Valenti, M.T. Transcription Factor Runx2 and its Application to Bone Tissue Engineering. Stem Cell Rev. Rep. 2011, 8, 891-897. [CrossRef] [PubMed]

45. Carbonare, L.D.; Valenti, M.T.; Zanatta, M.; Donatelli, L.; Cascio, V.L. Circulating mesenchymal stem cells with abnormal osteogenic differentiation in patients with osteoporosis. Arthritis Rheum. 2009, 60, 3356. [CrossRef] [PubMed]

46. Valenti, M.T.; Carbonare, L.D.; Donatelli, L.; Bertoldo, F.; Zanatta, M.; Cascio, V.L. Gene expression analysis in osteoblastic differentiation from peripheral blood mesenchymal stem cells. Bone 2008, 43, 1084-1092. [CrossRef]

47. Chong, P.-P.; Selvaratnam, L.; Abbas, A.A.; Kamarul, T. Human peripheral blood derived mesenchymal stem cells demonstrate similar characteristics and chondrogenic differentiation potential to bone marrow derived mesenchymal stem cells. J. Orthop. Res. 2012, 30, 634-642. [CrossRef]

48. Fei, D.; Wang, Y.; Zhai, Q.; Zhang, X.; Zhang, Y.; Wang, Y.; Li, B.; Wang, Q. KAT6A regulates stemness of aging bone marrowderived mesenchymal stem cells through Nrf2/ARE signaling pathway. Stem Cell Res. Ther. 2021, 12, 104. [CrossRef] [PubMed]

49. Valenti, M.T.; Carbonare, L.D.; Mottes, M. Role of microRNAs in progenitor cell commitment and osteogenic differentiation in health and disease (Review). Int. J. Mol. Med. 2018, 41, 2441-2449. [CrossRef]

50. He, Y.; Chen, Y. The potential role of lncRNAs in osteoporosis. J. Bone Miner. Metab. 2021, 39, 341-352. [CrossRef]

51. Zhang, K.; Shi, Z.; Ren, Y.; Han, X.; Wang, J.; Hong, W. Kcnq1ot1 promotes osteogenic differentiation and suppresses osteoclast differentiation. J. South. Med. Univ. 2021, 41, 31-38.

52. Zhou, Z.; Hossain, M.S.; Liu, D. Involvement of the long noncoding RNA H19 in osteogenic differentiation and bone regeneration. Stem Cell Res. Ther. 2021, 12, 74. [CrossRef] [PubMed]

53. Tong, X.; Gu, P.-C.; Xu, S.-Z.; Lin, X.-J. Long non-coding RNA-DANCR in human circulating monocytes: A potential biomarker associated with postmenopausal osteoporosis. Biosci. Biotechnol. Biochem. 2015, 79, 732-737. [CrossRef] 